\title{
A Simple Physical Model for Forest Fire Spread Rate
}

\author{
EUNMO KOO ${ }^{1}$, PATRICK PAGNI ${ }^{1}$, JOHN WOYCHEESE ${ }^{3}$, SCOTT STEPHENS ${ }^{2}$, \\ DAVID WEISE ${ }^{4}$, and JEREMY HUFF ${ }^{1}$ \\ ${ }^{1}$ Mechanical Engineering Department \\ ${ }^{2}$ Environmental Science, Policy and Management Department \\ University of California \\ Berkeley, CA 94720, U.S.A. \\ ${ }^{3}$ Fire Protection Engineering \\ Worcester Polytechnic Institute \\ Worcester, MA 01609, U.S.A. \\ ${ }^{4}$ Pacific Southwest Research Station \\ USDA Forest Service \\ Riverside, CA 92507, U.S.A.
}

\begin{abstract}
Based on energy conservation and detailed heat transfer mechanisms, a simple physical model for fire spread is presented for the limit of one-dimensional steady-state contiguous spread of a line fire in a thermally-thin uniform porous fuel bed. The solution for the fire spread rate is found as an eigenvalue from this model with appropriate boundary conditions through a fourth order Runge-Kutta method. Three experiments on fire spread are compared to the model simulations and good agreement is demonstrated. The comparisons with wind tunnel experiments on white birch fuel beds show that the physics in this model successfully evaluates wind and slope effects on the fire spread rate. The grassland fuel experiments with various fuel characteristics also compare well to the simulations. Limited comparison with data on fire spread in shrubs, obtained in China, also shows good agreement. These comparisons suggest that this model may serve as the basis for an improved operational model.
\end{abstract}

KEYWORDS: forest fire, grasslands, chaparral, fire spread rate, thermally-thin fuel bed

\section{NOMENCLATURE LIST}

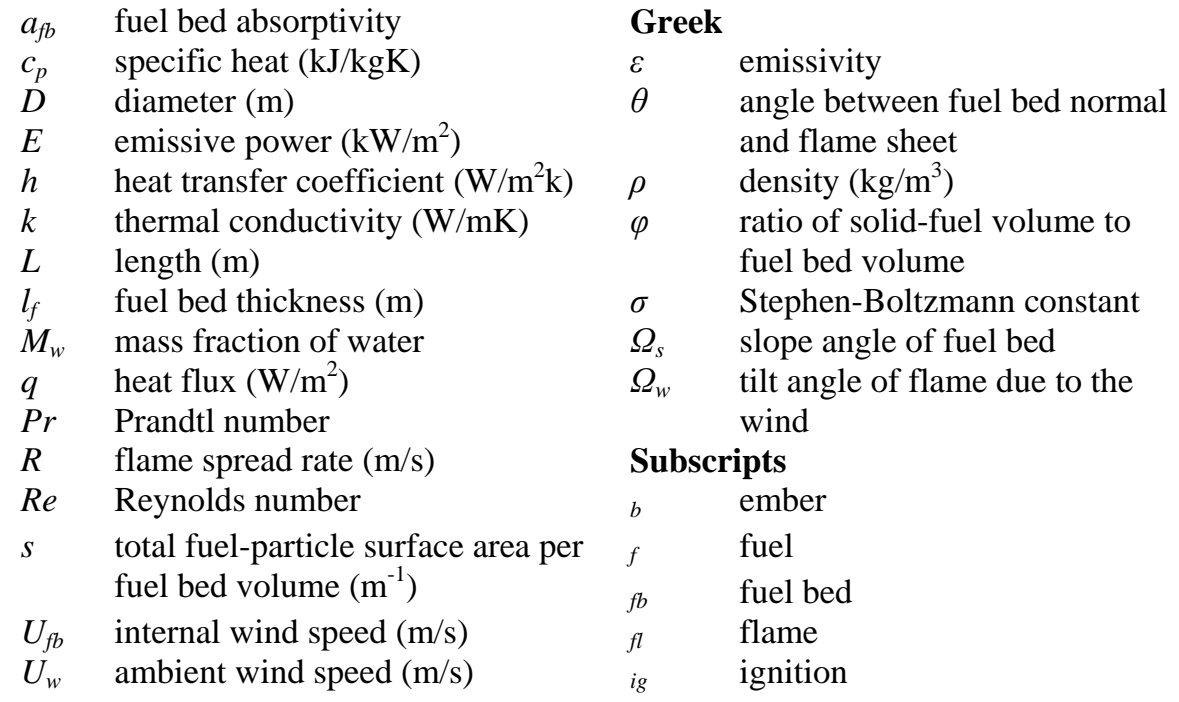

FIRE SAFETY SCIENCE-PROCEEDINGS OF THE EIGHTH INTERNATIONAL SYMPOSIUM, pp. 851-862 


\section{INTRODUCTION}

This study concerns steady-state modeling of contiguous spread of fire through a thin fuel bed. Chaparrals, grasses, pine needles and trees in the forest can be modeled as a layer of porous fuel, so this study can be used to predict spread rates for fires through these fuels. The thermally-thin limit is assumed to apply if the fuel bed thickness is small compared to the flame length. The spread rate of a fire is defined as the steady propagation speed of the flame front moving through this fuel layer. This steady-state combustion process of a fuel bed is driven by energy conservation within the fuel bed and heat transfer between the flame, the fuel bed and the ambient air. The flame is the only heat source in the system, so the shape of the flame - length and angle - is an important factor determining the spread rate. Other major factors include fuel bed porosity, fuel moisture content, fuel bed thickness, the slope of fuel bed, and the ambient wind speed. These parameters can be categorized into: fuel properties, fuel bed configuration, and ambient conditions.

Researchers have attempted to quantify fire spread rate for more than 50 years, and many mathematical models have been developed. Fons [1] first analyzed flame spread in forest fuels, assuming that the fuel was preheated to ignition by conductive, convective, and radiative heat transfer from the flaming zone. Emmons [2] discussed the mechanisms of forest fire spread and introduced a simple physics-based fire spread model for forest fires. Hotttel et al. [3] developed flame-spread models that included radiative and convective losses during preheating. Rothermel and Anderson [4] developed an empirical model for pine-needle fuel beds, which described the dependence of flame-spread rates on wind velocity and moisture content. Fang and Steward [5] evaluated the effects of fire spread rate parameters through lab-scale experiments with wood shavings as fuels. Rothermel [6] developed an empirical spread rate model for a wide variety of wildland fuels which led to the development of the BEHAVE [7] and FARSITE [8] operational models. However, his model assumes that wind and slope effects are additive and thereby may lack accuracy. Much research has been done to find the correct relationship between wind, slope and spread rate. Albini [9] developed a wildfire spread model with wind. Putnam [10] and Thomas [11] investigated the effects of wind on flame geometry. Pitts [12] provided a thorough review of wind effects on fire. Weise and Biging [13] built a statistical model based on laboratory experiments with white birch fuel. Pagni and Peterson [14] developed a physics-based flame spread model through porous fuels, and Mongia, Pagni and Weise [15] compared their model to Weise and Bigging's experimental results. Recently, Mabli [16] did flame spread experiments for grass fuels and developed modifications to the BEHAVE program inputs. Wu et al. [17] investigated surface burning of various fuel types such as shrubs and bamboo.

\section{ANALYSIS}

\section{Physical Model}

In this model, the fuel bed is assumed to be a thin, one-dimensional, homogenous, porous fuel layer. Since the fuel layer is thermally thin, there is no temperature difference between top and bottom surfaces at the same distance from the flame. This makes it possible to assume a one-dimensional fuel bed. The flame is also assumed to be a line fire; the flame is a two-dimensional sheet; its thickness is considered only in flame 
emissivity calculations. This assumption also implies that chemical reactions are infinitely fast. The system reference frame is attached to the flame sheet. Thus, the flame is fixed at the origin $(y=0)$ and the fuel bed is moving toward the flame sheet at a constant spread rate, $R$. The assumption of a constant spread rate, which implies steadystate combustion, has been validated experimentally for uniform fuels and ambient flows.

Figure 1 shows the schematic of the physical model and the coordinate system. The flame, which is of length $L_{f l}$ and angle $\theta$ relative to the normal to the fuel bed, is placed at the origin. $U_{w}$ is the ambient wind speed, which is parallel to the fuel bed. $\Omega_{s}$ is the angle between the fuel bed normal and gravity vector, so it is the slope of the fuel bed.

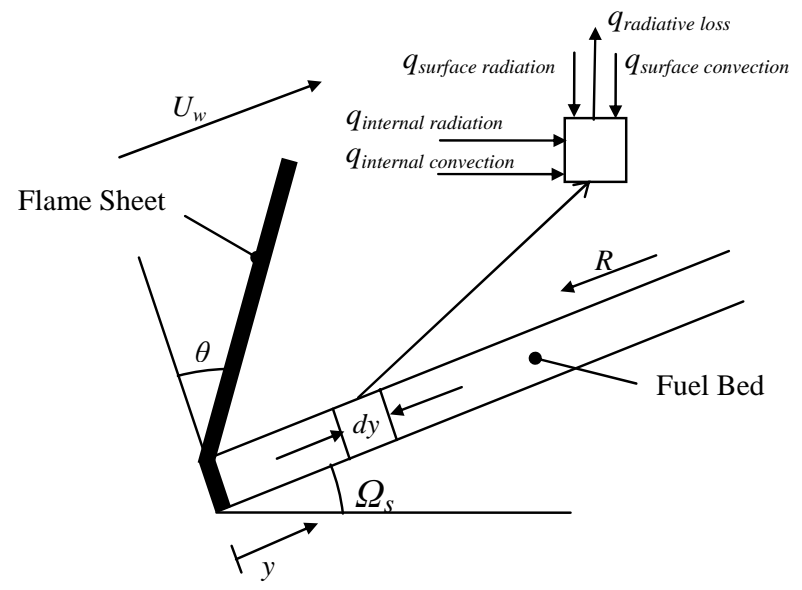

Fig. 1. Flame spread schematic.

Before local ignition, the fuel bed is heated by the flame to the ignition temperature, $T_{\text {ig }}$. Thus, the fuel temperature is a function of the distance $y$ from the flame. At $y=\infty$, the fuel is at the ambient temperature, $T_{\infty}$, and at $y=0$, the fuel is at the ignition temperature, $T_{i g}$.

\section{Energy Conservation}

Energy is conserved in every fuel element as shown in Eq. 1. The left hand side is the sum of the energy absorbed and used for raising the temperature or evaporating the moisture within the fuel bed element. The right hand side of Eq. 1 is the sum of all possible heat transfer mechanisms for a fuel element. The lower fuel bed surface is assumed to be adiabatic and impermeable.

$$
\begin{aligned}
q_{\text {sensible }}+q_{\text {latent }} & =q_{\text {sr }}(\text { surface radiation })+q_{\text {ir }}(\text { internal radiation }) \\
& +q_{r l}(\text { radiative loss }) \\
& +q_{s c}(\text { surface convection })+q_{i c}(\text { internal convection })
\end{aligned}
$$

Conductive heat transfer through fuel bed is neglected. Radiative heat transfer can occur in three ways: surface radiation, internal radiation, and radiative loss, which is radiative heat transfer from the fuel bed to the ambient surroundings. Convective heat transfer can occur both on the surface and inside the fuel bed. Within the approximations of steady state spread through a thin fuel bed, the accuracy of the mathematical model depends on how well the terms in Eq. 1 are modeled. 
The left hand side of Eq. 1 is the energy absorbed in each fuel element. This energy transfer from the flame is required to sustain the flame at the origin, i.e., required to maintain the ignition temperature at the origin. For the fuel element of length $d y$, the sensible energy required at distance $y$ per unit fuel bed volume per unit time is:

$q_{\text {sensible }}=\left\{\begin{array}{cl}-\rho_{f} c_{p f} R \phi \frac{d T}{d y}, & \text { at } T \neq 373 K, \\ 0 & \text { at } T=373 K,\end{array}\right.$

where $\rho_{f}$ is the fuel particle density, $c_{p f}$ is the fuel bed specific heat capacity, $\varphi$ is the volume of solid fuel per unit fuel bed volume (i.e., packing ratio), and $T$ is the fuel temperature at $y$. The energy is assumed to evaporate the moisture in the fuel only when the temperature of fuel reaches the assumed boiling temperature of water, 373K. It may be expressed as

$q_{\text {latent }}=\left\{\begin{array}{cl}\rho_{f} h_{\text {vap }} R \phi \frac{d M_{w}}{d y}, & \text { at } T=373 K, \\ 0 & \text { at } T \neq 373 K,\end{array}\right.$

where $h_{v a p}$ is the specific enthalpy change of water to vapor at $373 \mathrm{~K}, M_{w}$ is the mass fraction of water, i.e., the mass of water per wet fuel bed mass at $y$. Evaporation in fuel elements not at the boiling temperature is assumed to be negligible.

\section{Radiation}

The flame radiative emissive power is $E_{f l} \approx \varepsilon_{f l} \sigma T_{f l}{ }^{4}$, where the $T_{f l}$ is the flame temperature and $\varepsilon_{f l}$ is the flame emissivity. It is assumed that the flame is an isothermal sheet with uniform emissivity, so that the emissive power is uniform. Thus, radiation from the flame to each element at $y$ on the top surface of the fuel bed is:

$$
q_{\text {surface radiation }}=\frac{a_{f b^{E} f l}}{2 l_{f}}\left(1-\frac{Z}{\left(1+Z^{2}\right)^{1 / 2}}\right) \tanh \left(\frac{2}{3}\left(\frac{w}{L_{f l}}\right)^{1 / 3}\right) \text {, }
$$

where $w$ is the width of the fuel bed, $l_{f}$ is the thickness of the fuel layer, $L_{f l}$ is the flame length, and $Z=\left(y / L_{f l}-\sin \theta\right) / \cos \theta$. $Z$ is a result from the crossed strings method for determining view factors. The tilt angle of the flame, $\theta$, is the sum of $\Omega_{s}$ and $\Omega_{w} . \Omega_{w}$ is the tilt angle due to the wind and approximated as $\Omega_{w}=\tan ^{-1}\left[1.4 U_{w}\left(g L_{f l}\right)^{-1 / 2}\right]$ as determined by Putnam [10]. The hyperbolic tangent term in Eq. 4 takes into account the finite width of the fuel bed and gives good agreement with 3D view factors.

The flame emissivity is a function of the gas emissivity and the soot emissivity as described by Bard and Pagni [18]. Using the soot properties for wood fuel obtained experimentally [18], the flame emissivity $\varepsilon_{f l}$ can be approximated as in Eq. 5 with the flame mean beam length proportional to $L_{f l}$ and an effective total absorption coefficient of $0.6 \mathrm{~m}^{-1}$ : 
$\varepsilon_{f l}=1-e^{-0.6 L_{f}}$.

Within the porous fuel bed, unburned fuel receives radiative heat flux through the fuel bed volume from the ember zone. This internal radiation exponentially decays with distance $y$ from the burning zone as described by Hottel $[3,14]$ :

$$
q_{\text {internal radiation }}=0.25 \mathrm{~s} E_{b} \exp (-0.25 \mathrm{sy}) \text {, }
$$

where $s$ is the total fuel-particle surface area per fuel-bed volume and the ember emissive power is $E_{b} \approx \varepsilon_{b} \sigma T_{b}{ }^{4}$. The ember emissivity is assumed to be one and the ember temperature is assumed to be the ignition temperature.

Unburned fuel elements lose heat to the ambient by the radiative heat loss at the top surface of the fuel bed:

$q_{\text {radiative losses }}=-\frac{\varepsilon_{f b} \sigma\left(T(y)^{4}-T_{\infty}^{4}\right)}{l_{f}}$.

\section{Convection}

Convective heat transfer is defined as heat transfer between the fuel bed and the ambient air due to bulk fluid motion. The effects of buoyancy are neglected; only forced convective heat transfer due to the ambient wind is included. Thus, there is no convection unless an ambient wind exists. The fuel bed exchanges heat with the air by convection both on the surface and in the interior and may be heated or cooled by convective heat transfer. Fig. 2 shows the definitions of either upslope or downslope, heading or backing fires.

Figure 1 might suggest that the flame serves as an impermeable barrier. However, according to Beer [19], the wind can penetrate the flame sheet due to three dimensional effects. Thus, here the wind is approximated as plug flow blowing straight through the flame. Inside a sufficiently porous fuel bed, the wind can also be assumed to produce plug flow with a uniform velocity proportional to both porosity and the ambient wind velocity, $U_{f b}=(1-\varphi) U_{w}$.

For surface convection, the flame temperature $T_{f l}$ is used as a gas reference temperature for heading cases and $T_{\infty}$ is used for backing cases. For heading cases, the temperature difference is assumed to exponentially decay with distance $y$ from the flame [14]. The heat transfer coefficient for plug flow over the flat surface is used [20]. The convective heat transfer to the top surface of the fuel bed is then:

$$
\begin{aligned}
& q_{\text {surface convection, heading }}=\frac{0.565 k_{f l} \operatorname{Re}_{y}{ }^{1 / 2} \operatorname{Pr}^{1 / 2}}{y l_{f}}\left(T_{f l}-T(y)\right) e^{-0.3 y / L_{f}}, \\
& q_{\text {surface convection,backing }}=\frac{0.565 k_{\infty} \operatorname{Re}_{\left(L_{\beta b}-y\right)}{ }^{1 / 2} \operatorname{Pr}^{1 / 2}}{\left(L_{f b}-y\right) l_{f}}\left(T_{\infty}-T(y)\right) .
\end{aligned}
$$




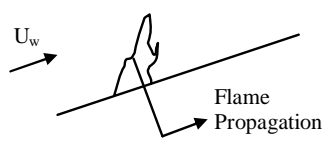

Upslope (positive slope) Heading (wind-aided)

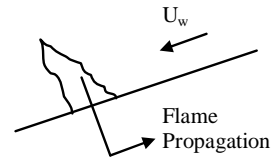

Upslope (positive slope) Backing (wind-opposed)
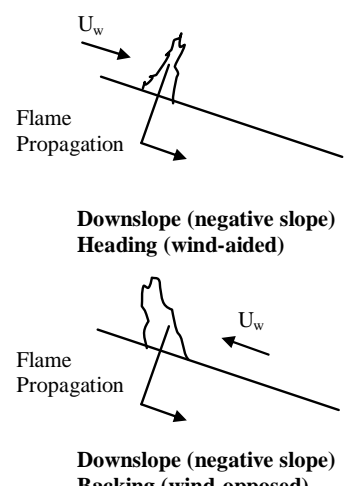

Backing (wind-opposed)

Fig. 2. Wind and slope configurations.

The convective heat transfer coefficient for a single cylinder in cross flow is used for the interior of fuel bed [21]. It is assumed that fuel elements are comprised of cylinders, which represent branches or needles. The porosity of the fuel bed is large enough to use the heat transfer coefficient for a single cylinder rather than banks of cylinders in crossflow. Equation 9 represents the convective heat transfer inside the fuel bed. Note that the Reynolds numbers in Eq. 8 and Eq. 9 are different. The length scale in Eq. 8 is the fuel bed coordinate and the velocity is $U_{w}$; the length scale in Eq. 9 is the branch diameter, $D$, and the velocity is $U_{f b}$.

$q_{\text {internal convection, heading }}=\frac{0.911 s k_{b} \operatorname{Re}_{D}^{0.385} \operatorname{Pr}^{1 / 3}}{D}\left(T_{b}-T(y)\right) e^{-0.25 s y}$,

$q_{\text {internal convection,backing }}=\frac{0.911 s k_{\infty} \operatorname{Re}_{D}^{0.385} \operatorname{Pr}^{1 / 3}}{D}\left(T_{\infty}-T(y)\right)$.

\section{Solution Method}

To solve Eq. 1 for $T(y)$ and the eigenvalue, $R$, two boundary conditions are needed:

$$
\begin{array}{lll}
T(0)=T_{i g} ; & M_{w}(0)=0 & \text { at } y=0, \\
T(\infty)=T_{\infty} ; & M_{w}(\infty)=M_{w \infty} & \text { at } y=\infty .
\end{array}
$$

A fourth order Runge-Kutta method is used iteratively, adjusting the spread rate, $R$, until the ignition temperature exists at the origin. The fuel temperature is assumed to be fixed once it reaches $373 \mathrm{~K}$ until all the fuel moisture is removed. Typical temperature and moisture profiles are shown in Fig. 3a. Figure $3 b$ shows typical heat flux contributions to the fuel bed calculated with Eqs. 1-10. 

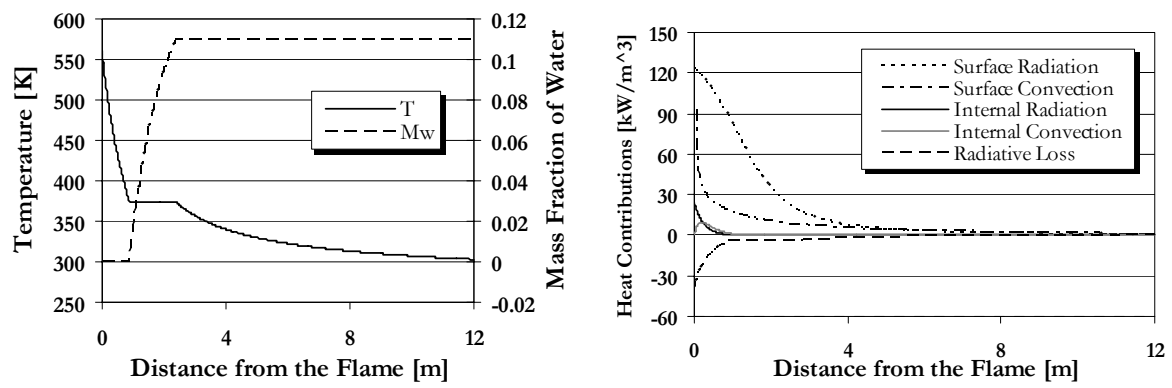

Fig. 3. (a) Temperature and mass fraction of water profiles; (b) various heat flux contributions. These calculations are for a white birch wind tunnel experiment [13]. ( $+17^{\circ}$ slope, $1.1 \mathrm{~m} / \mathrm{s}$ wind , $\left.L_{f}=1.69 \mathrm{~m}\right)$; $R: 0.061 \mathrm{~m} / \mathrm{s}$ (exper.), $0.062 \mathrm{~m} / \mathrm{s}$ (calc.).

The surface radiation appears to be the dominant heat flux contribution, as shown in Fig. 3b, for heading, upslope cases with larger spread rates. Either the radiative loss or the convective heat transfer at the surface is the second most important term. In these cases, heat exchange at the surface of the fuel bed appears to dominate heat transfer mechanisms inside of the fuel bed.

\section{RESULTS}

Three different sets of experiments have been simulated with this flame spread model. First, Weise's experiments on white birch in a wind tunnel were simulated [13]. Mongia et al. [15] have compared their model with the same data and better agreement is obtained here. Weise's experiments provided all four cases shown in Fig. 2. Mabli's experiments [16] were no-wind, no-slope cases, but they had a variety of fuel characteristics. Also Mabli used the BEHAVE program for comparison with her experiments, which allows comparison of this model's results with those of the BEHAVE model. Thirdly, the data gathered by Wu et al. [17] on surface fire spread rates in shrubs and litter under a pine forest have been compared to this model's simulations. In the case of Weise's experiments, all the fuel characteristics and the fuel bed geometry were well-described. For Mabli's data and Wu's data, some fuel characteristics and properties, which were not described in their papers, were estimated from other sources [19-22]. Table 1 shows the input variables and their ranges used in these calculations.

\section{White Birch Experiments}

Weise's experimental data for flame spread on very porous white birch fuel beds in a laboratory wind tunnel are compared to this model. The purpose of the experiments was to examine wind and slope interaction effects on flame properties. A tilting wind tunnel with an adjustable roof and $2.5 \mathrm{~m}$ long by $0.9 \mathrm{~m}$ wide test section was employed. 
Table 1. Input variables and their ranges for fire spread model calculations.

\begin{tabular}{|l|c|c|c|c|}
\hline \multicolumn{1}{|c|}{ Name } & Units & $\begin{array}{c}\text { Weise } \\
\text { (white birch) }\end{array}$ & $\begin{array}{c}\text { Mabli } \\
\text { (grass) }\end{array}$ & $\begin{array}{c}\text { Wu et al. } \\
\text { (shrub) }\end{array}$ \\
\hline Flame length $\left(L_{f l}\right)$ & $\mathrm{m}$ & $0.08-1.69$ & $0.7-1.4$ & 1.3 \\
\hline Ambient wind speed $\left(U_{w}\right)$ & $\mathrm{m} / \mathrm{s}$ & $-1.15-+1.15$ & 0 & 3 \\
\hline Fuel bed slope $\left(\Omega_{s}\right)$ & $\circ$ & $-17-+17$ & 0 & 15 \\
\hline Fuel density $\left(\rho_{f}\right)$ & $\mathrm{kg} / \mathrm{m}^{3}$ & 609 & 200 & 560 \\
\hline Fuel particle surface/volume $(s)$ & $\mathrm{m}^{-1}$ & 17.5 & 1000 & 5.7 \\
\hline Initial water mass fraction & - & 0.11 & $0.07-0.17$ & 0.16 \\
\hline Packing ratio $(\varphi)$ & - & 0.008 & $0.06-0.145^{\mathrm{a}}$ & $0.0026^{\mathrm{a}}$ \\
\hline Diameter of branch $(D)$ & $\mathrm{m}$ & 0.00252 & 0.001 & 0.0022 \\
\hline Fuel bed width $(w)$ & $\mathrm{m}$ & 0.686 & 1 & 30 \\
\hline Fuel bed thickness $\left(l_{f}\right)$ & $\mathrm{m}$ & 0.114 & $0.05-0.33$ & 0.7 \\
\hline Fuel bed absorptivity $\left(a_{f b}\right)$ & - & 0.6 & 0.6 & 0.6 \\
\hline Fuel bed emissivity $\left(\varepsilon_{f b}\right)$ & - & 0.9 & 0.6 & 0.9 \\
\hline Ambient temperature $\left(T_{\infty}\right)$ & $\mathrm{K}$ & 303 & 303 & 297 \\
\hline Flame temperature $\left(T_{f l}\right)$ & $\mathrm{K}$ & 1083 & 1083 & 1083 \\
\hline Ignition temperature $\left(T_{i q}\right)$ & $\mathrm{K}$ & 561 & 561 & 561 \\
\hline Fuel specific heat $\left(c_{p f}\right)$ & $\mathrm{kJ} / \mathrm{kgK}$ & 2500 & 1250 & 2800 \\
\hline
\end{tabular}

${ }^{\mathrm{a}}$ Packing ratios were estimated from the fuel loads $\left(\mathrm{kg} / \mathrm{m}^{2}\right)$ and fuel bed thicknesses $(\mathrm{m})$ with assumed fuel densities $\left(\mathrm{kg} / \mathrm{m}^{3}\right)$.

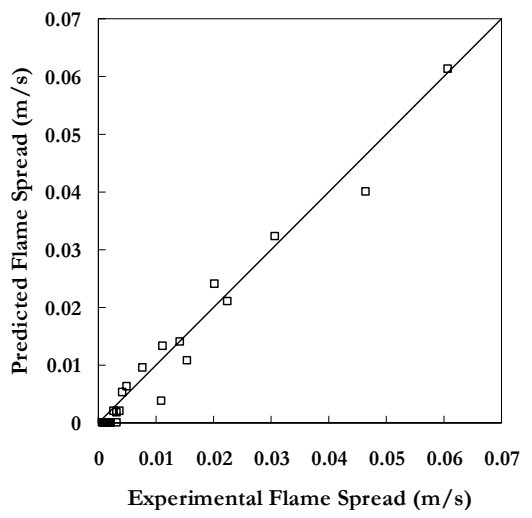

Fig. 4. Comparison of predicted and experimental flame spreads for white birch fuel in a wind tunnel for various wind and slope conditions; wind:

$-1.15 \mathrm{~m} / \mathrm{s}$ to $+1.15 \mathrm{~m} / \mathrm{s}$, slope: $-17^{\circ}$ to $+17^{\circ}$.

An open-topped wind tunnel was used to remove any effects that a ceiling may have on the buoyancy of the flame. Wind velocities of $-1.15,-0.4,0,+0.4$, and $+1.15 \mathrm{~m} / \mathrm{s}$ were combined with slopes of $-17,-8.5,0,+8.5$, and +17 degrees. Wind was induced by a commercially available three-blade, $0.75 \mathrm{~m}$ diameter, free-standing rotary fan that was placed at either end of wind tunnel depending on the type of fire spread desired. The adjustable roof was gradually extended behind the flame during each experimental fire to insure a relatively constant wind velocity without impeding buoyancy. The fuel bed consisted of vertical white bitch (Betula papyrifera Marsh.) sticks $(139.7 \times 4.55 \times$ $1.1 \mathrm{~mm}$ ). The mean fuel loading was $0.43 \mathrm{~kg} / \mathrm{m}^{2}$ for this fuel bed. The mean surface area to volume ratio was $22.75 \mathrm{~cm}^{-1}$. The mean fuel moisture of the sticks was $\sim 11 \%$ [13]. 
Figure 4 shows comparisons of predicted and experimental spread rates for these white birch fuels. Good quantitative agreement is illustrated for all data points. The fuel characteristics and test conditions of these wind tunnel experiments were well-controlled and well-documented, so the model should have good agreement and it does. To see wind and slope effects more clearly, the same data points are plotted as a function of the wind and slope conditions in Fig. 5.

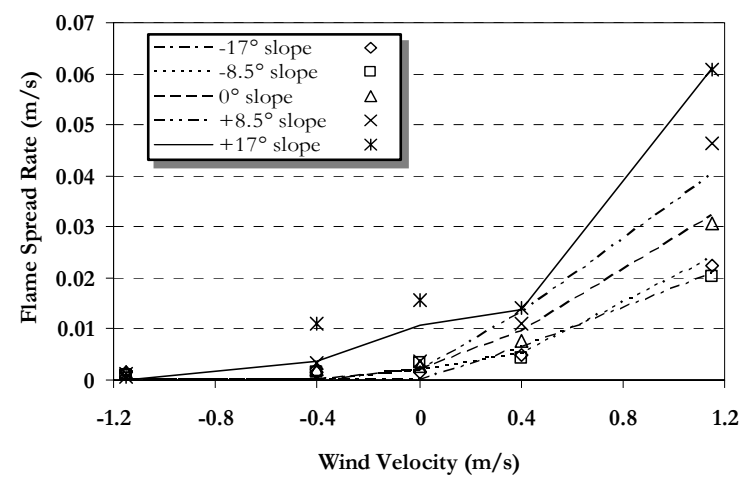

Fig. 5. Predicted flame spread rates (lines) and experimental flame spread rates (symbols) for white birch fuel with wind and slope conditions.

\section{Grassland Fuel Bed Experiments with No Wind and No Slope}

Mabli [16] experimented on backing grassland fire spread rates. Here, the term of "backing" is used for a no-wind, no-slope condition. $1 \mathrm{~m} \times 1 \mathrm{~m}$ fuel beds freshly cut from wild grassland plots were used. These comparisons show the effectiveness of this model for a wide range of fuel characteristics. Because real grass was used, the fuel bed depth couldn't be uniform through out the fuel bed, so average fuel bed thicknesses are used. In Mabli's experiments, the fuel moisture range is 6 to $22 \%$, the fuel load range is 0.164 to $1.27 \mathrm{~kg} / \mathrm{m}^{2}$, and the fuel bed depth range is 0.06 to $0.33 \mathrm{~m}$.
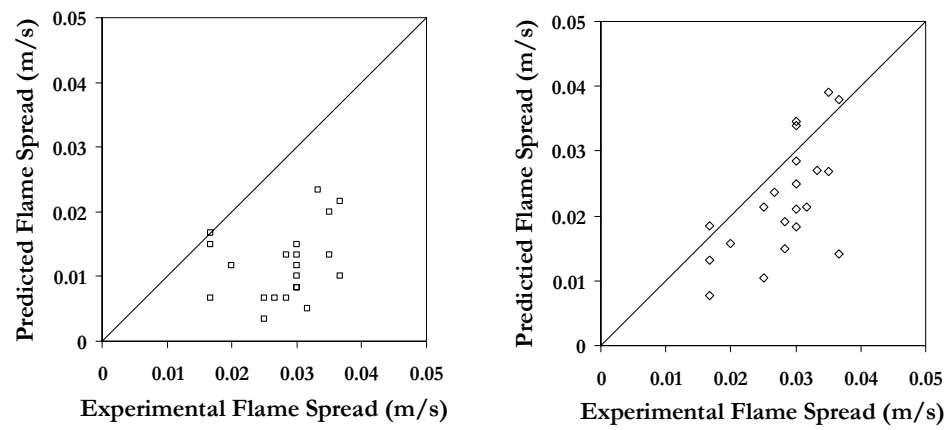

Fig.6. Comparisons of experimental flame spread rates vs. (a) BEHAVE predictions $[7,16]$; (b) predictions of this model for no-wind and no-slope.

Figure 6a, which is from Mabli's dissertation [16], shows comparisons of experiments with BEHAVE simulations. Figure 6b shows comparisons of Mabli's experiments and the simulations run here. In Fig. 6a, nineteen out of twenty simulations are underestimated. With this model, even though the predictions still underestimate the experiments, the general trend represents better agreement. Since this model focuses on 
conditions with wind and slope effects, the reasonable agreement with no-wind and noslope experiments is encouraging.

\section{Under-story Burning of Shrubs in a Pine Forest}

To further test the range of this model the experimental data of $\mathrm{Wu}$ et al. [17] were also compared to simulations. The case of shrub fuels was selected from the five experimental fuels studied by $\mathrm{Wu}$ et al. since more fuel characteristics were reported for the shrubs. Litter and living shrubs were measured as surface fuel. The slope of the test section was 15 degrees, the ambient temperature was $297 \mathrm{~K}$, the relative humidity was $60 \%$ and the wind was heading at $3.0 \mathrm{~m} / \mathrm{s}$. The surface fuel was $0.7 \mathrm{~m}$ thick. Litter fuel loading was $0.9 \mathrm{~kg} / \mathrm{m}^{2}$ and the moisture content of the litter fuel was $14.2 \%$. The living shrub fuel loading was $0.13 \mathrm{~kg} / \mathrm{m}^{2}$ and the moisture content of the shrub fuel was $61.8 \%$. The observed flame height was $1.3 \mathrm{~m}$. Blending the litter and shrub properties as weighted averages as shown in Table 1, the simulation gave a flame spread rate of $0.052 \mathrm{~m} / \mathrm{s}$, which is close to the experimental result of $0.050 \mathrm{~m} / \mathrm{s}$.

\section{CONCLUSIONS}

A simple model for flame spread in a thin porous fuel bed has been developed based on energy conservation and the heat transfer mechanisms between the flame, the fuel bed and the ambient. With appropriate boundary conditions, the flame spread rate was found as an eigenvalue. Forty-six experiments were simulated (25 white birch sticks, 20 grassland fuel and 1 shrub fuel). Good agreement has been shown. In comparison to wind tunnel experiments on white birch stick fuel beds, the model predicted flame spread rates accurately and showed the model's ability to deal with wind and slope effects. With the grassland fuel experiments, various fuel conditions were simulated and generally better agreement was achieved than with BEHAVE. The simulation of flame spread in shrub and surface fuels beneath a pine forest also showed reasonable agreement. The accuracy of the predictions depends on the reliability of the input parameters, such as fuel characteristics, wind and slope conditions, and flame length. Future work will be aimed at improving the accuracy of each term in the heat transfer sub-models [22] and at independent prediction of the flame length [23] which currently needs to be provided experimentally. This is an inherently over-simplified model, but hopefully it may play some role in the efforts of the USDA Forest Service to revise their operational models.

Future work will also explore another mechanism that conveys energy from the flame to the unburned fuel. Piloted ignitions by firebrands landing well in front of current fire lines have long been observed and studied [24-27]. However, this phenomenon also contributes to contiguous flame spread by the mechanism of firebrands which land immediately in front of the spreading flame. Adding this mechanism to both simple and complex [28] spread models is a future challenge.

\section{ACKNOWLEDGEMENT}

The authors are very grateful for the financial support provided by the United StatesDepartment of Agriculture-Forest Service under grant number 02-JV-11272166-073. The authors also appreciate the assistance of B. Miner and M. Peters.

\section{REFERENCES}

[1] Fons, W.L., "Analysis of Fire Spread in Light Forest Fuels," Journal of Agricultural Research, 72, pp. 93-121, (1946). 
[2] Emmons, H., "Fire in the Forest," Fire Research Abstracts and Review, 5, pp. 163-178, (1963).

[3] Hottel, H.C., Williams, G.C., and Steward, F.R., "The Modeling of Firespread through a Fuel Bed," Proceedings of Tenth International Symposium on Combustion, the Combustion Institute, Pitts., PA, 1965, pp. 1099-1107.

[4] Rothermel, R.C., and Anderson, H.E., "Fire Spread Characteristics Determined in the Laboratory,” USDA Forest Service Research Paper INT-30, Ogden, UT, 1966.

[5] Fang, J.B., and Steward, F.R., "Flame Spread through Randomly Packed Fuel Particles," Combustion and Flame, 13, pp. 392-398, (1969).

[6] Rothermel, R.C., "A Mathematical Model for Predicting Fire Spread in Wildland Fuels," USDA Forest Service Research Papers INT-115, Ogden, UT, 1972.

[7] Andrews, P.L., "BEHAVE: Fire Behavior Prediction and System: BURN Subsystem, Part 1,” USDA Forest Service Research Papers INT-194, Ogden, UT, 1986.

[8] Finney, M.A., "FARSITE: Fire Area Simulator - Model Development and Evaluation,” USDA Forest Service Research Papers RMRS-RP-4, Missoula, MT, 1998.

[9] Albini, F.A., "A Model for the Wind Blown Flame from a Line Fire," Combustion and Flame, 43, pp. 155-174, (1981).

[10] Putnam, A.A., “A Model Study of Wind-blown Free-burning Fires," Proceedings of Tenth International Symposium on Combustion, The Combustion Institute, Pitts., PA, 1965, pp. 1039-1046.

[11] Thomas, P.H., "The Size of Flames from Natural Fires,” Proceedings of Ninth International Symposium on Combustion, The Combustion Institute, Pitts., PA, 1963, pp. 844-859.

[12] Pitts, W.M., "Wind Effects on Fires," Progress in Energy and Combustion Science, 17, (2), pp. 83-134, (1991).

[13] Weise, D.R., and Biging, G.S., "A Qualitative Comparison of Fire Spread Models Incorporating Wind and Slope Effects," Forest Science, 43, (2), pp. 170180, 1997.

[14] Pagni, P.J., and Peterson, T.G., "Flame Spread through Porous Fuels," Proceedings of Fourteenth International Symposium on Combustion, The Combustion Institute, Pitts., PA, 1973, pp. 1099-1107.

[15] Mongia, L.M., Pagni, P.J., and Weise, D.R., "Model Comparisons with Simulated Wildfire Flame Spread Data," The Western States Section of the Combustion Institute, pp. 98S-68, 1998.

[16] Mabli, L.A., "Modeling Backing Fires in California Grassland Fuels," Doctoral Dissertation, Environ. Sci., Policy and Management Dept, UC Berkeley, CA, 2001. 
[17] Wu, D., Yi, S., and Liu, A., "Understory Burning in Stands of Masson’s Pine," Fire Safety Science -- Proceedings of the Seventh International Symposium, International Association for Fire Safety Science, London, UK, 2003, pp. 545556.

[18] Bard, S., and Pagni, P.J., "Spatial Variation of Soot Volume Fractions in Pool Fire Diffusion Flames," Fire Safety Science -- Proceedings of the First International Symposium, International Association for Fire Safety Science, London, UK, 1985, pp. 361-369.

[19] Beer, T., “The Interaction of Wind and Fire,” Boundary-Layer Meteorology, 53, pp. 287-308, (1991).

[20] Kays, W.M., and Crawford, M.E., Convective Heat and Mass Transfer, McGraw-Hill, New York, 1993, p. 165.

[21] Incropera, F.P., and DeWitt, D.P., Fundamentals of Heat and Mass Transfer, John Wiley and Sons, New York, 1996, p. 340.

[22] Byram, G.M., Clements, H.B., Bishop, M.E., and Nelson, R.M. Jr., "Final Report - Project Fire Model: An Exploratory Study of Model Fires,” Office of Civil Defense Contract OCD-PS-65-40, USDA Forest Service, Asheville, NC, 1966.

[23] McCaffrey, B., "Flame Height," The SFPE Handbook of Fire Protection Engineering, $2^{\text {nd }}$ ed., DiNenno, P.J., et al., eds., National Fire Protection Association, Quincy, MA, 1995, pp. 2-1 to 2-8.

[24] Tarifa, C.S., del Notario, P.P., and Moreno, F.G., "On the Flight Paths and Lifetimes of Burning Particles of Wood," Proceedings of Tenth International Symposium on Combustion, The Combustion Institute, Pitts., PA, 1965, pp. 1021-1037.

[25] Vodvarka, F., "Firebrand Field Studies - Final Report,” IIT Research Institute, IITRI Final Technical Report No. J6148, Chicago, IL, 1969.

[26] Woycheese, J. P., Pagni, P.J., and Liepmann, D., "Brand Propagation from Large-Scale Fires,” Journal of Fire Protection Engineering, 10, (2), pp. 32-44, 1999.

[27] Woycheese, J.P., "Brand Lofting and Propagation from Large-Scale Fires," Doctoral Dissertation, Mechanical Engineering Dept., UC Berkeley, CA, 2000.

[28] Linn, R.R., Reisner, J., Colman, J.J., and Winterkamp, J., "Studying Wildfire Behavior Using FIRETEC,” International Journal of Wildland Fires, 11, (4), pp. 233-246, 2002. 